\title{
The perceived impact of employee turnover and its outcome on the efficiency of the organizational performance
}

\author{
Hanan Suleiman Salim Al Amri Middle East College \\ Jitendra Pandey \\ Middle East College
}

The problem of employee turnover is very important in any organization. The impact of displacing an employee differ based on many factors, including the hardness of the position. To study the impact, we prepare a questionnaire and distribute it online with people working in Oman. However, there is not many studies highlighted the employee turnover. Employee turnover is a measurement of numbers of employee who left their works or organization and there are two types of employee turnover, voluntary and involuntary.

Therefore, the aim of this research is to examine the problem and understand it, which consists of three elements: analyze the cause, determine the impact of employee's performance, and provide solutions and recommendation based on findings. This research focuses on the impact of staff turnover on organizational effectiveness and employee performance within Oman. High staff turnover rate may jeopardize efforts to attain organizational objectives. In addition, when an organization loses a critical employee, there is negative impact on innovation, consistency in providing service to guests may be jeopardized and major delays in the delivery of services to customers may occur. The research design used in this study was the quantitative approach, which allowed the researcher to use structured questionnaires when collecting data.

A pilot study was conducted to test the questionnaire. The survey method was used in this study because the target population only composed of 100 employees. A high response rate of $88 \%$ was obtained using the personal method of data collection, questionnaire was structured in a 5-point Likert scale format. The Statistical Package for Social Science (SPSS) version 15 for Windows was used for statistical analysis of the main responses. The study finding suggests that salary is the primary cause of staff turnover in the Department of Home Affairs. The findings highlighted that high staff turnover increases workload to the present employees in the department. The study finding also showed that staff turnover causes reduction in effective service delivery to the customers and reflects poorly on the image of the Department. Other findings suggested that unhealthy working relationship may also be the cause of staff turnover in the department. The recommendations highlighted that top management should pay a marketable salary to employees and the employees must be rewarded if they have achieved their goals. Top management should also develop opportunities for career advancement in the department. Top management should involve employees when they make key decisions that will affect them in the organization. The study concludes with direction for future research.

\section{Introduction}

Employees are the real asset for any organization to ensure its sustainability in the industry. 


\section{Journal of Student Research}

Fourth Middle East College Student Research Conference, Muscat, Sultanate of Oman

Therefore, it is very essential for any organization to pay great attention to them. For the employees to remain working in the company for a long period, they should feel happy and satisfied with their jobs in the company. Employee turnover continues to occur nonstop since the last few years and it is one of the sustainable issues that has been faced by human resource management for decades. It has a negative influence on the labor force situation, organizational performance, society in general, and the individual particularly (Ozolina 2017:14).

Employee turnover is a measurement of the numbers of an employee who left them works or organization and there are two types of employee turnover, voluntary and involuntary. Voluntary turnover is the employee who left the organization by them self and it happens because of many reasons like they want to move from the organization to other or it can be for a better job opportunity. Involuntary turnover is when the organization or employer fair or layoffs the employee for many reasons like economic problems or poor performance or other reasons. It is very important to highlight this issue because the problem exists in contemporary time. Employee turnover force many organizations and companies to close. It is happening in the real life in the chosen company. The research outcomes are to find solutions for this problem and reduce it. (Bamboohr n.d).

Employee turnover is the biggest problem that is faced in many organizations in Oman and there are many negative effects of employee turnover. According to a published article on gethppy (n.d) outlines different views of the previous researcher regarding this topic such as Corcoran and Fursso. Corcoran (n.d) defines employee turnover: " Employee turnover is a situation where employees exit the organization voluntary for various reasons or are relieved by the organization, most times negatively in terms of costs and the capacity to deliver the minimum required service. " the new employee needs to be trained, as well as they, want some time to know more about work so that they can be productive. According to Fursso (2015) in his study into the causes and effects of employee turnover, he states that: " Employee turnover is one of the most studied and important issues to the organizations and one that needs special attention.

" stated that the organization's effectiveness is the theme of how useful an organization is in attaining the outcomes, the organization wishes to produce. (Muhammad, Ghafoor, \& Naseer, 2011) also narrated that the effectiveness of an organization is a theoretical concept and it is impossible to determine. Instead of assessing organizational effectiveness, the organizations establish proxy measures and further used as a tool to represent organizational effectiveness. Such things may be included as management efficiency, the employee's performance, employee's core competencies, number of employee's served and population segments with respect to types and sizes served (Muhammad, Naseer, Sheraz, \& Mahfooz, 2012). A high alert warning rate is a decrease in motivation among the organization, which is one of the factors that affect the organization productivity. One of the negative effects of employee turnover is productivity effects. Employee production and general firm performance can be negatively affected when a higher employee turnover. As it is mentioned earlier that employee turnover is leading to losing the trained staff and who knows all the organization goals and role in achieving the organizational goals.

Chosen power and desalination company are published in May 2005. The company is involved in the electricity generation of water which is provided to citizens. (GPCO 2016). Since 2011 involuntary employee turnover is starting in the company and it may happen because of the petrol price or the economic problem, and in 2018 the main office of the company announce that they are going to close, and they are going to do stuff layoffs. Up to this time, the fate of the staff is not known and there is no solution found. (Al J 2017)

\section{The Research Problem}

Many companies try their best to retain their potential employees by giving them their own space 


\section{Journal of Student Research}

Fourth Middle East College Student Research Conference, Muscat, Sultanate of Oman

to express their opinion freely, get involved with what they are thinking, make them happy and increase their level of job satisfaction. They also support them and build a good relationship between the employer and employee, by increasing their compensation, benefits and other remuneration in order to make the employee want to stay in the company for a long time (Heathfield 2018). Despite this, many companies suffer from a high ratio of employee turnover and employee dissatisfaction. This problem occurs when the employer treats the team members differently and discriminates between them as regards the workload. Furthermore, work culture has a great impact on employee productivity. If the employees are not happy with their job, this will reduce their performance, which has a negative impact on organizational performance (Reynolds 2017). In response to this problem, this research intends to examine several options to reduce the level of employee turnover in chosen company and increase the organization's profit, which would lead to the growth of the company as well. The aim of this research is to address the problem in chosen Company and to find a radical solution to the problem. Furthermore, this research intends to evaluate the performance assessment for the reasons for employee turnover. As it will explore and analyze the effects on the employees. The ability to work as a team, and participate in information collection regarding the company, where it will enhance the work procedures effectively and efficiency.

\section{Impact of Employee Turnover on the organization's Performance}

The rate at which employees leave an organization has had a significant negative impact on the performance of an organization. Employee turnover in an organization may be caused by various factors, which may sometimes be out of control of the organization or even sometimes because of controllable elements. Employees in an organization are crucial stakeholders directly related to the performance of an organization. Different organizations have different structures, and hence the criteria of employee hierarchy differ from one place to another. The external factors that lead to employee turnover cannot be controlled while the internal elements can be controlled to reduce the rate at which the employees leave the organization. In addition, the employees of an organization are the key components that help the organization in its process of growth and development and in building its image and general reputation in public. Therefore, it is quite evident that its employees determine the success of an organization. For instance, organizations that encourage team building among its employees are viewed to be successful because employees are united together towards achieving a common goal (Felps 2009). Besides, an organization that incorporates allowances and rewards as motivational factors to its employees help in enhancing their employees' job satisfaction levels and hence encouraging its employees to work hard in their various departments towards achieving a common goal of the organization.

Employee turnover can be a big problem for the large, medium and small organization. All organizations can expect a certain degree of employee turnover. In fact, a certain degree of rotation staff may be desirable since then, creates opportunities to offer new efficiency, ideas, and expertise to the organization, as well as provide career development opportunities for existing workers. Although employee turnover, however, it is both costly to individual organizations and the economy. It also affects morale, profitability, efficiency, and productivity as well.

High turnover of staff may jeopardize efforts to achieve the organizational objectives. More than that when the organization loses an active staff or employee, the impact occurs innovation and consistency in providing customer service delivery customers may be adversely affected. Turnover has positive and negative effects on the organization. Employee turnover can introduce new ideas and skill in the company. However, it can lead to difficulties in attracting new employees.

Hiring new employee will require a lot of time limit and budget for the organization. The hiring process for several positions requires advertising, screening, interviewing and training. If an employee leave and to hire new employee will require a lot of budget. This will be time-consuming. 
It will require enough budget to hire new employees. Cost-benefit analysis can be done before hiring an employee (Buyens and DeVos 2014). If an employee is unable to provide the desired output on providing certain kind of facilities it will result in the loss to the organization.

There are consequences of high turnover of both financial and non-financial. High turnover can be a serious abstract to productivity, quality and profitability in companies, the high turnover rate means that just having enough staff to meet daily tasks in a challenge, even beyond the question of how well the staff is available. (Johonson 2009).

According to Ayesh, director manager of Flagship Consultancy: "Employee turnover has always been one of the invisible enemies of business in any growing economy; it is invisible because of most costs associated with a statement or reported at the end of fiscal year". (Anonymous 2008).

\section{Organization's Reputation}

High turnover ratio of employee will affect the organization performance in a negative way. The employee, which leave the organization in a pathetic condition, he will certainly tell about the organization in a negative way. This will result in the negative reputation of the organization. Which is not admirable for the reputable organizations.

\section{Hiring the Wrong Candidates}

If any organization is unable to hire the right candidate for the right post, then this will result in negative impact. That it is unable to hire the right candidate for the job. Therefore, the organization must hire the right candidate for the right post. As he/she should have enough abilities for the job so that he/she can perform well. Conductance of training would be time and resource consuming for those employees who does not possess the adapt ability. Moreover, it will also leave a negative impact on the output of organizational performance. Thus, the right candidate must be selected for the post.

\section{Challenges Faced by the Organization}

According to Frost (2018), employee turnover has a negative impact on the organization efficiency. It is important to understand the effect of losing the company its potential employee. For the organization to generate profit and for more appealing work environment, the company should work hard to reduce the turnover rate. Knowing the serious consequences of leaving the employee their jobs in advance can help the company avoid many future losses.

\section{Time}

When the employee leaves the company, his position will be vacant, and the company must find who will fill it. There are many processes should be done to find the right candidate. The managers in the human resources will spend lots of time in advertising for the vacancy, conducting exit interviews, recruiting and selecting the most talented candidates and interviewing them. While the colleagues and the supervisor are responsible to cover that vacancy until the new employee is hired and begins working (Frost 2018).

This whole process is very time consuming, the new employee until he achieves competency in the position and fully learn his job, he might take several months or years.

\section{Cost}

Frost (2018) states that when the employee applies for a resignation letter and walks out the door, 
he/she will cost the organization lots of money. All the money invested in the employee in training programs, licensing and education gone with the employee leaving the company. In addition, now the company must start from the beginning, the company will spend the same cost for the replacement employee in order to prepare him/she for the position. Other expenditure may include physical test, drug testing and moving expenses. Furthermore, the company pays money on advertising the new vacancy.

\section{Productivity}

According to Frost (2018), she strongly emphasizes that with higher employee turnover rate the productivity of the work frame tends to decrease. Since a new employee will join the company, he will have a period of adjustment to learn the work. The replacement will take longer time to complete the tasks that assigned to him. He will not be able to finish the work quickly and at the same quality of the previous employee. If there a group project that depends on the new employee, the work of the group may slow done due to the replacement. This absolutely will affect the level of productivity of the experienced employee. When an employee resigns the loss of momentum will also affect moral. Moreover, when the employee leaves the company this will add stress and burden on the existing employee that to fill the void. Great employee may leave the company because they no longer can handle the stress of doing everything by their own (Leonard 2018).

\section{Continuity}

The continuity of services to customers and another employee may get affect due to the high employee turnover rate. This will appear in industry that values and relies heavily on the relationship with clients. If a client used to purchase product from the company on a regular basis they will always want to deal with the same employee. The customers will not accept to deal with new employee. In order to build a strong loyalty consistent relationship with customers is required and very important. This can be advantage for the company to provide well trained employees that doesn't change as well as high quality services (Frost 2018).

\section{Employee Retention, Employee Satisfaction, and Employee Turnover}

The main challenge facing employer today is to retain the staff assigned to their organization. In the area of ring competition, each organization tries to achieve the best level of providing the best facilities for its employees. Satisfying human resources is one of the most difficult tasks facing most 


\section{Journal of Student Research}

Fourth Middle East College Student Research Conference, Muscat, Sultanate of Oman

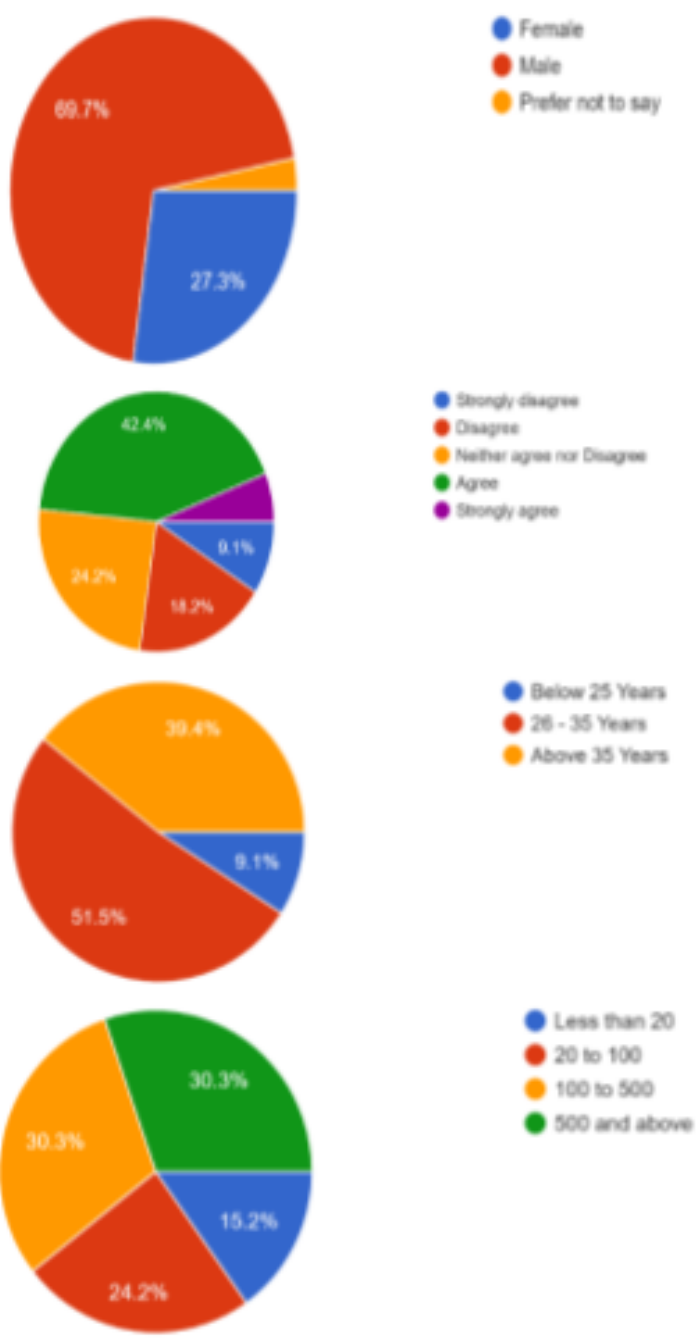

Figure 1. Population Details for the survey 


\section{Journal of Student Research}

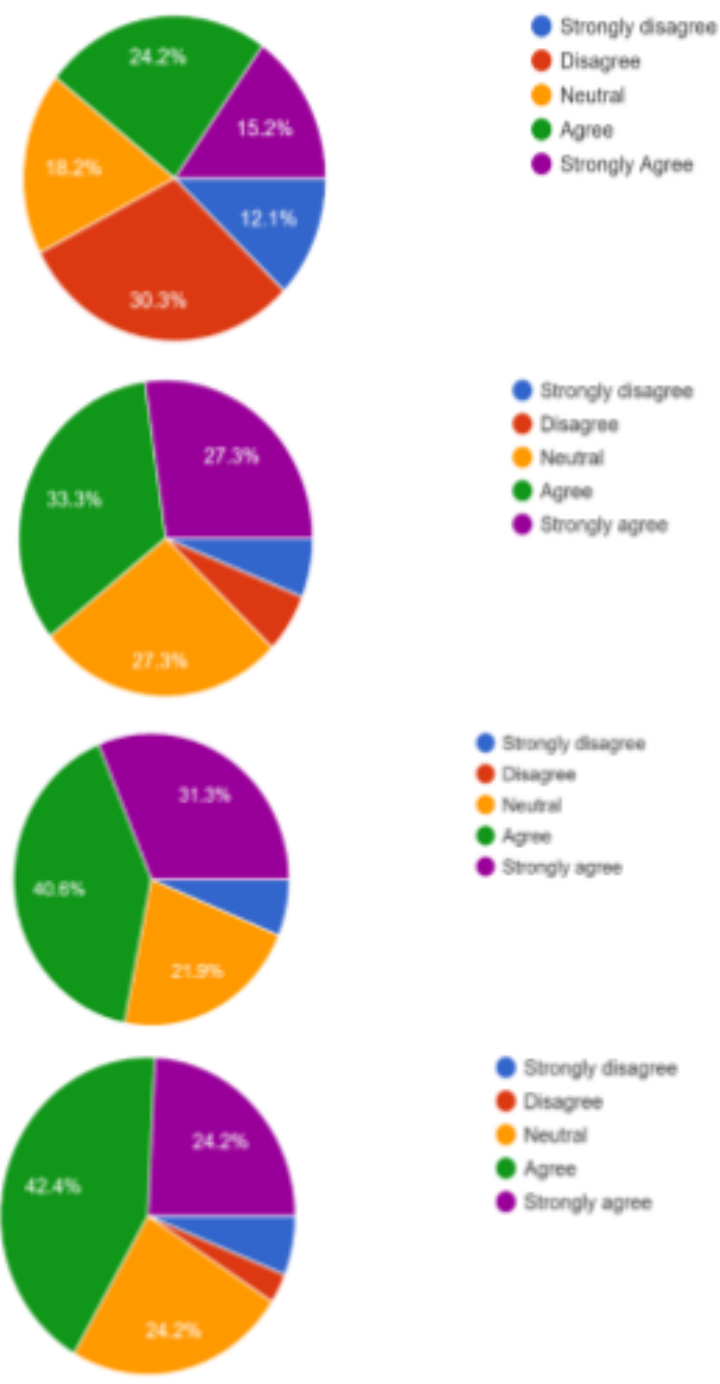

Figure 2. Organizational Support

organizations today. Understanding and knowing what goes on in the human mind is very difficult to understand. Along with many opportunities for skilled and talented human resources, it becomes very difficult for employers to satisfy and retain them. There is no single strategy or retention plan, which may satisfy every employee in the organization. As we have different personalities in their own demands and different expectations of the organization. According to Arnold and Feldman 1982; Wotruba and Tyagi 1991; Brodie 1995, they found and concluded in their study that age, job satisfaction, tenure, job image, met expectations, and organizational commitment are constantly linked to the intentions of rotation and actual turnover. Research findings by Jewell and Segall 1990; Locke 1976, they clearly stated that people who are satisfied with their jobs tend to stay longer and be less absent. Researchers such as Carsten and Spector 1987 conducted a metaanalysis of the relationship between job satisfaction and turnover of employees and found a negative relationship between the two variables. Harrington et al. 2001, examining various predictors of intentions left a function noted that emotional exhaustion. Lower levels of core job satisfaction and dissatisfaction with salary and promotion opportunities were the main predictors. Randhawa 2007 concluded in her study that there is a marked relationship between job satisfaction and employee turnover intent, which suggests increased job satisfaction, which is the low intention of the individual to leave the job.

\section{Data Analysis}




\section{Journal of Student Research}

Fourth Middle East College Student Research Conference, Muscat, Sultanate of Oman

The demographic graph in Figure 1 illustrates the number of the employee in the respondent's organization. 30.3\% number of the employee in respondent's organization are 100 to 500 and above. Following with $24.2 \%$ number of the employee in respondent's organization have 20 to 100 employees. On the other hand,15.2\%of the respondents had less than 20 employees in their organization. The majority of respondents $42.4 \%$ agree that the company maintains salary levels and benefits which compared well to other companies. On the other hand, $24.2 \%$ of the respondents neither agree nor disagree that it is easy to get along with their colleagues in the company.

Around $48.5 \%$ of the respondents agree that the supervisor deals with employee fairly. While $24.2 \%$ of the respondents neither agree or disagree, and 15.2 of the respondents strongly disagree with fact of this statement.

Over $45 \%$ of the respondents agree that their immediate manager recognize, encourage, and appreciates their work. This percentage indicates that the respondents are satisfied with their job when it comes to their manager.

Over $30 \%$ of the respondents remained neither agree or disagree, while $48.5 \%$ of respondents are agree that they can voice their opinion without fear.

Over $42.4 \%$ of respondents had positive prospective toward that there is adequate opportunity for them to move to better job within the company. This indicates that there is career growth and career development in their company.

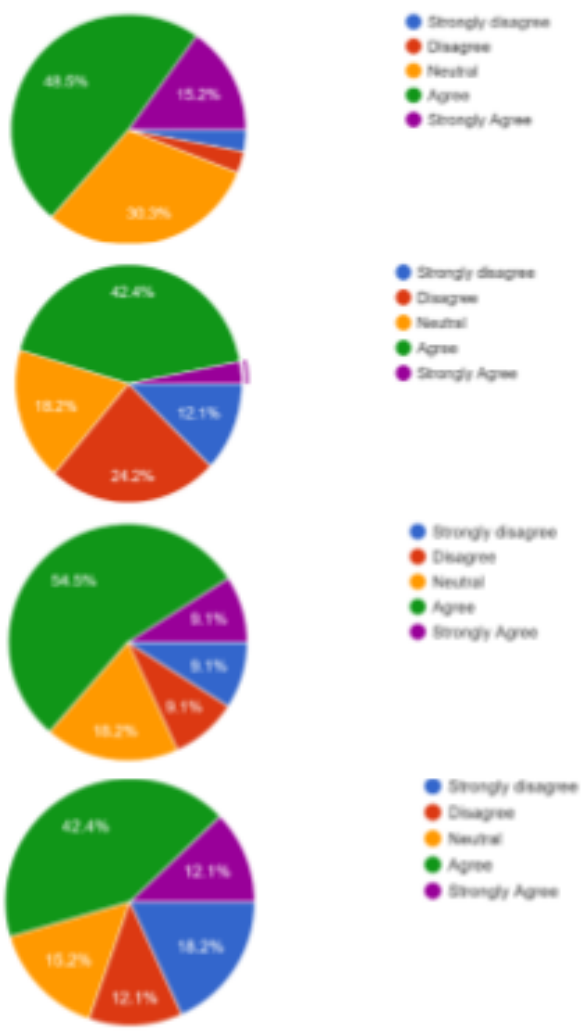

Figure 3. Support by colleagues and resources 


\section{What are the reasons for employee turnover in your opinion?}

\section{3 responses}

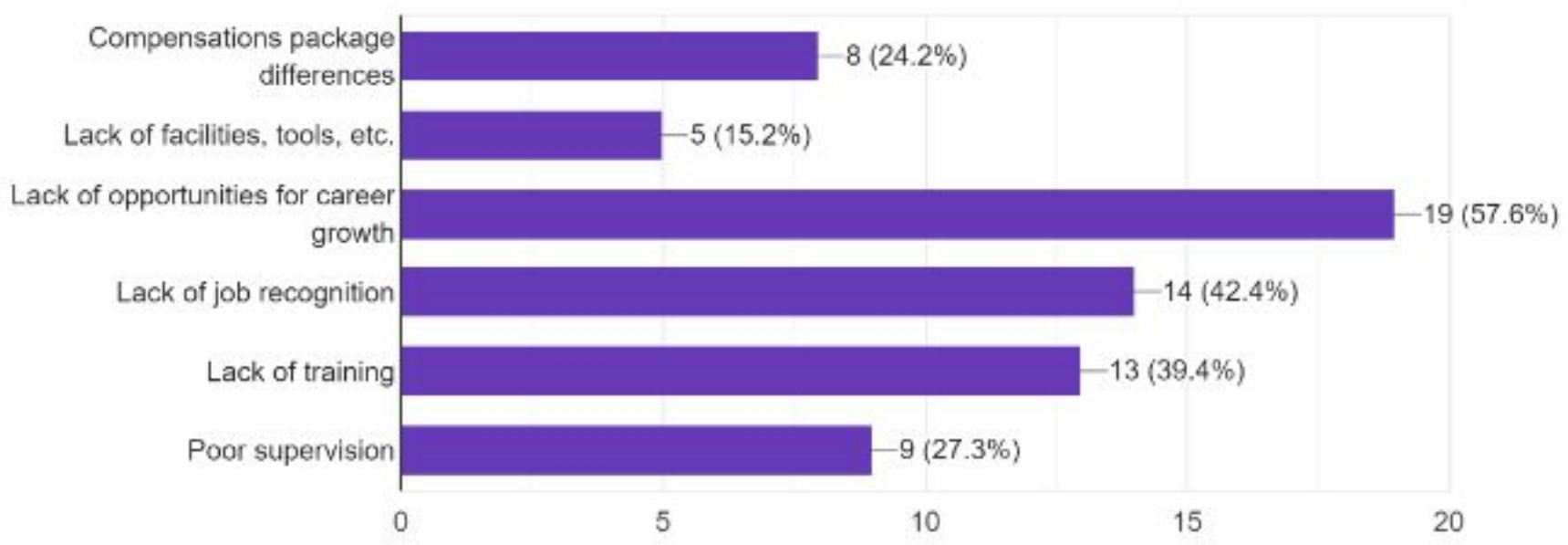

Figure 4. The Causes of Employee Turnover According to the Respondents

From Figure 5, it can be concluded that majority of respondents believe that lack of opportunity for career growth is the greatest element that contributes to employee turnover. Followed by the job recognition, which is part of the career growth, employees, would not leave in case the company offers better pay. The least factor among all is lack of facilities, tools, etc. Were rated by $15 \% \%$ of the respondents. It indicates that few respondents believed inadequate training for a job or position could cause turnover. However, compensations and poor supervision have $24.2 \%$ and $27.3 \%$ of the respondents.

\section{Which element is more important for better employment opportunities?}

\section{3 responses}

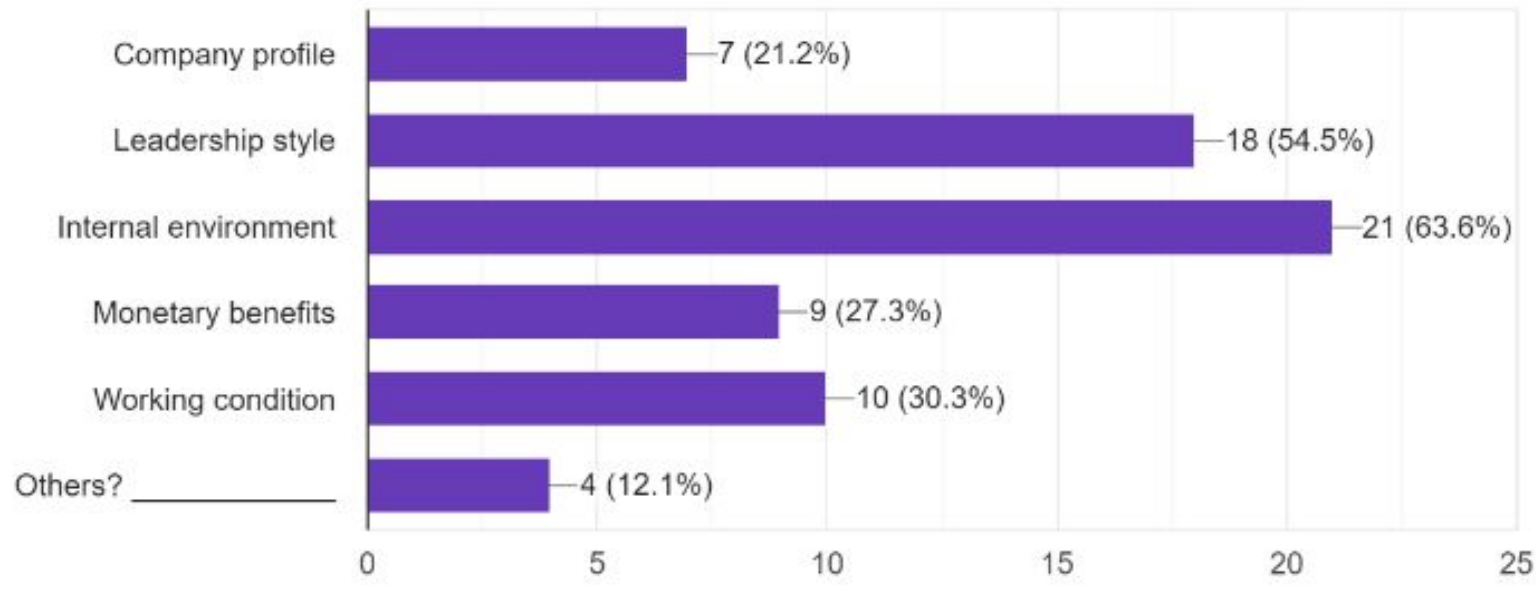

Figure 5. Factors of Better Employment Opportunities 
Concerning this question, figure 6 shows the highest percentage of respondents believed that the most significant element that contributes to better employment opportunities is internal environment. Close to this that attract employee to an organization is leadership style where $54.5 \%$ of the respondents selected this factor. While $27 \%$ of the respondents choose monetary benefit. However, the company profile accumulates only $21.2 \%$ showing that few of the respondents are indeed concerned with the company profile for which they work or wish to work for.

\title{
According to you, what are the ideas that can reduce the employee turnover in the organizations?
}

\author{
32 responses
}

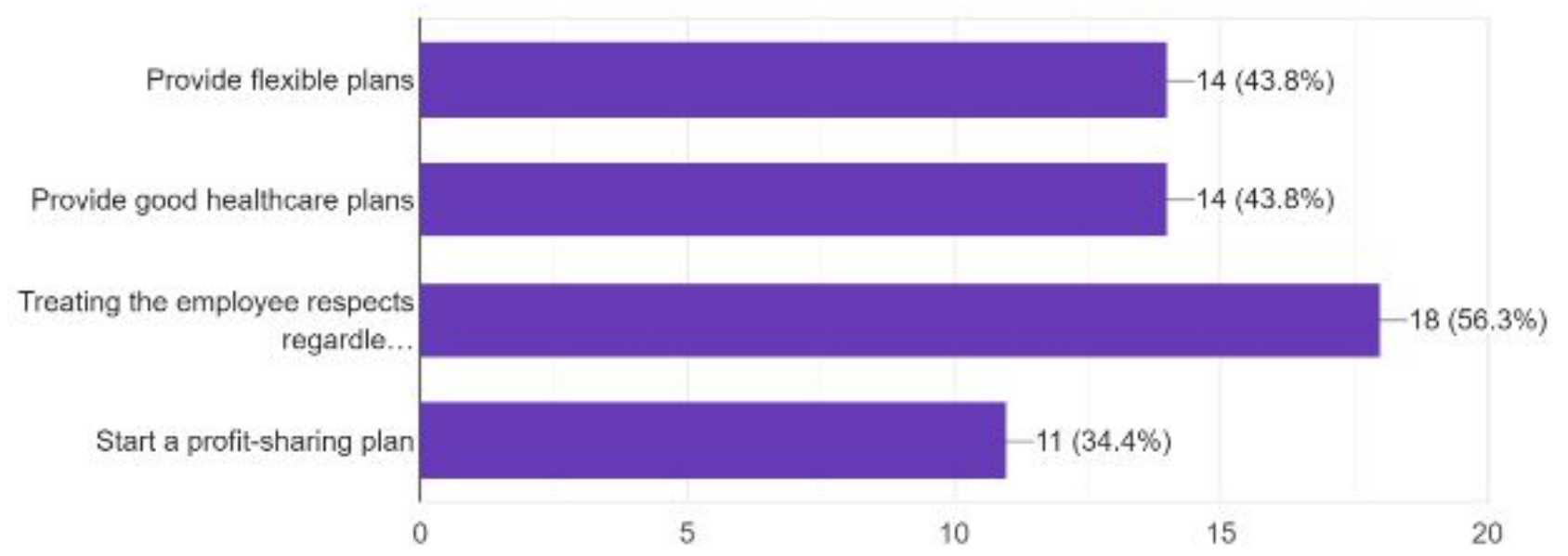

Figure 6. Ideas that Smart Companies apply to Reduce Turnover Issues

Figure 7 chart illustrates what ideas does smart companies implement toward employee turnover. The organizations make use of competitive salaries to attract talented as well as skilled employees to work for them. The significant percentage, which is $56.3 \%$ of the respondents, choose training the employee and respects regardless of their job or position as their first option. It thus shows that companies use this approach to minimize employee turnover. However, the second-best approach is that most welcome and used by an organization is provide good healthcare plans and provide flexible plan. Where, $43.8 \%$ of the respondents believes in this idea. On the other hand, the leas method used is start a profit-sharing plan where only $34 \%$ of the respondents choose this method.

\section{Conclusion}

In conclusion, this article included many of the problems faced by employees within organizations. This research also highlights the key factors responsible for employee retention within organizations. The survey was conducted using the open link and response was taken from employees across Oman. No specific organization is highlighted in the result. The trend shows that the employees prefer to work within a collaborative environment and employee friendly organization.

\section{Acknowledgements}

I offer all the pride and gratitude to Mr. Jitendra Pandey for his assistance and accomplishment 


\section{Journal of Student Research}

Fourth Middle East College Student Research Conference, Muscat, Sultanate of Oman

throughout the work of this article, and that I value all the useful and exerted efforts that he has given, his suggestions and experiences have helped us throughout our career in this article. Today, I am pleased to thank Mr. Jitendra for the concerted efforts made, which contributed to the advancement of the work to provide the best possible, although this indicates the painstaking efforts that did not wait for them, thank you and praise, So I am pleased to thank you for all you deserve.

\section{References}

E-BANKING FRAUDS AND FRAUD RISK MANAGEMENT,( Mr. Rupesh. D. Dubey and Dr. Anita Manna)2019, available at < http://oldtm.lbp.world/SeminarPdf/167.pdf > . reserve banks of India, India central bank , 2019 , available at,$<\underline{\text { https://www.rbi.org.in/scripts/otherlinks.aspx }>}$

MBA Knowledge Base , Kate ,August 22, 2010, available at

<https://www.mbaknol.com/business-finance/recent-trends-in-indian-banking-sector/ >

Digital banking fraud: Best practice for technology-based prevention ,2019, available at $<$ https://netguardians.ch/digital-banking-fraud/>

Bank fraud, From Wikipedia,2019, available at <https://en.wikipedia.org/wiki/Bank_fraud>

Five examples of user-centered bank fraud, Andre Machado,2019, available at <https://www.helpnetsecurity.com/2019/08/02/user-centered-bank-fraud/ >

Fraud risk management A guide to good practice, January 2009, available at < https://www.cimaglobal.com/Documents/ImportedDocuments/cid techguide fraud_risk_managemen t_feb09.pdf.pdf $>$

Iyer, N. and Samociuk, M., (2006), Fraud and Corruption: Prevention and Detection.

CIMA and the IBE, (2008), Managing responsible business

Collier, P.M. and Agyei-Ampomah, S., (2007), CIMA Offi cial Learning System Management Accounting Risk and Control Strategy.

The Institute of internal auditors, The Association of certifi ed public accountants, The Association of certifi ed public examiners, (2008), Managing the business risk of fraud: A practical guide.

Fraud Advisory Panel, (2006), Fighting Fraud: A guide for SME’s 2nd Edition.

Fraud poses serious risks to banks, Oman Daily Observer, $12 \mathrm{Jul} 2018$, available at <https://www.pressreader.com/oman/oman-daily-observer/20180712/281917363845980> 